\title{
Políticas Públicas de saúde à População LGBT: Percepção das travestis que se prostituem diante da realidade da cidade de Confresa - MT
}

\section{Cleyton Geovani Kremer de Cesaro Licenciado e Bacharel em Ciências Sociais/ UNEMAT}

\begin{abstract}
Resumo: Estudos relacionados à homossexualidade e saúde vêm sendo amplamente realizados no último século, porém no que tange o processo de inclusão das travestis neste serviço, pouco se é discutido. E com este direcionamento, a presente pesquisa busca identificar a percepção das travestis em prostituição, do município de Confresa-MT, frente aos atendimentos nos estabelecimentos públicos de saúde. Sabe-se que as questões de gênero e sexualidade sempre foram tabus na sociedade, porém a violação dos direitos dos homossexuais às políticas públicas, principalmente do universo composto pelas travestis, leva-nos a preocupação diante dos estigmas e preconceitos que condicionam esta população à uma intensa vulnerabilidade. Diante dos resultados obtidos, pode-se entender que as ações de saúde não condizem com as reais necessidades das travestis, assim como relatam a constante presença de preconceito e estigma advindo de profissionais e pacientes que também fazem uso destes serviços. Sendo assim, tornam-se necessárias reformulações nos espaços de saúde e transformações no modo de pensar e agir dos profissionais, através da implantação de ações que sanem as necessidades destes atores sociais.
\end{abstract}

Palavras-chave: Políticas Públicas; Saúde; Homossexualidade; Travestilidade; Preconceito. 


\title{
Public health policies to the LGBT population: Perception of transvestite prostitutes before the reality of the city of Confresa- MT
}

\begin{abstract}
Homosexuality and health-related studies have been widely conducted in the last century, but regarding the process of inclusion of transvestites in this service, little is discussed. And with this direction, this research aims to identify the perception of transvestites in prostitution, the city of Confresa-MT, compared to care in public health facilities. It is known that gender and sexuality issues have always been taboo in society, but the violation of the rights of homosexuals to public policies, especially the universe composed of transvestites, leads us to concern about the stigmas and prejudices that influence this population at one intense vulnerability. Based on these results, one can understand that health actions are not consistent with the real needs of transvestites, as well as report the constant presence of prejudice and stigma arising professionals and patients who also make use of these services. Therefore, become necessary restatements in healthy spaces and transformations in the way of thinking and acting of professionals through the implementation of actions that resolve the needs of these stakeholders.
\end{abstract}

Keywords: Public Policy; healthy; homosexuality; travesti; prejudice.

\section{Políticas de salud pública a la población LGBT: La percepción de las prostitutas travestis en la realidad de la ciudad de Confresa- MT}

Resumen: la homosexualidad y los estudios relacionados con la salud han sido ampliamente llevado a cabo en el siglo pasado, pero en relación con el proceso de inclusión de travestis en este servicio, se discute poco. Y con esta dirección, esta investigación tiene como objetivo identificar la percepción de los travestis que ejercen la prostitución, la ciudad de Confresa-MT, versus la atención en los centros de salud públicos. Se sabe que las cuestiones de género y sexualidad siempre ha sido tabú en la sociedad, pero la violación de los derechos de los homosexuales en las políticas públicas, en especial el universo compuesto de travestis, nos lleva a la preocupación por los estigmas y prejuicios que influyen en esta población en un intensa vulnerabilidad. Sobre la base de estos resultados, se puede entender que las acciones de salud no son coherentes con las necesidades reales de los travestis, así como el informe de la presencia constante de los profesionales y los pacientes prejuicio y el estigma que surge que también hacen uso de estos servicios. Por lo tanto, se convierten en reajustes necesarios en espacios de salud y transformaciones en la manera de pensar y actuar de los profesionales a través de la implementación de acciones que respondan las necesidades de estos grupos de interés.

Palabras clave: políticas públicas; salud; la homosexualidad; travesti; prejuicio. 


\section{Introdução}

Os Movimentos Sociais LGBT1 (Lésbicas, Gays, Bissexuais, Travestis e Transexuais) vêm concretizando, não apenas no Brasil, mas no mundo, um aumento da visibilidade, dando ênfase às denúncias de violência e ao desrespeito dos direitos humanos destes grupos sociais, passando os mesmos a reivindicarem igualdade dos direitos e políticas públicas que contemplem suas necessidades.

Portanto, o presente estudo, apresenta como seu objeto de pesquisa a percepção das travestis de Confresa-MT2, que se prostituem frente aos atendimentos nos estabelecimentos de saúde pública e o cumprimento das políticas públicas de saúde voltadas a esta população, neste município. O objetivo deste trabalho é analisar como estão sendo direcionadas as políticas de saúde em âmbito municipal à esse grupo de pessoas e se os estabelecimentos de saúde estão aptos a receber a população LGBT, em cumprimento às diretrizes que regulam e estabelecem a saúde destes atores sociais.

Este recorte populacional foi proposto, tendo em vista que o preconceito direcionado as travestis em prostituição encontra-se duplamente presente, partindo da hipótese de que são estigmatizadas tanto pelo fato de serem propriamente travestis e também por praticarem a prostituição, práticas estas que aparecem como violações dos princípios e das normas, tendo em vista os conceitos de gênero e trabalho impostos em nossa sociedade, utilizam da heteronormatividade e do trabalho formal como legíveis e imprescindíveis para um convívio social harmonioso e correto.

A prostituição entre travestis no município de Confresa-MT vem aumentando nos últimos anos e, nestas circunstâncias, identifica-se a necessidade de implantação políticas públicas que sanem as problemáticas enfrentadas por esta parcela populacional. Levando a necessidade de ressaltar a importância da promoção de uma saúde de qualidade destinada a esses atores sociais, que mesmo representando uma pequena parcela da sociedade, apresentam-se vulneráveis, tanto no que tange ao próprio ato de prostituir-se, quanto a violência sofrida em seu dia-a-dia, devido a estigmas e à heteronormatividade3 presente na sociedade, que os leva a um processo preocupante, de muitas vezes não procurarem os serviços de saúde, ou ainda, se procurarem, não obterem resolutividade.

Terto Jr. (2002) relata que neste último século, as relações entre homossexualidade e saúde têm se tornado motivo de muitos debates e controvérsias, partindo das análises tanto das ciências sociais como das ciências médicas. Tendo como parâmetro a extensa perspectiva da saúde, a atenção à saúde da população LGBT não deve ser considerada apenas a partir do ponto de

1 LGBT - Lésbicas, Gays, Bissexuais, Travestis, Transexuais - Variadas siglas fazem referencia a população homossexual, porém todas recorrem às abreviações das terminologias adotadas em que a posição dasletras podem mudar conforme a ordem em que aparecem expostas. Nas siglas em que se utilizam apenas uma letra "T" (LGBT, GLTB, dentre outras), segundo Cardoso e Ferro (2012), esta letra é utilizada para se referir aos Travestis e Transexuais.

2 Estado de Mato Grosso

$3 \mathrm{O}$ termo heteronormatividade diz respeito à regulação e normatização modos de ser e de viver os desejos corporais e sexuais conforme o que está estabelecido socialmente, sempre levando em consideração a perspectiva biológica e determinista, apresentando somente duas possibilidades de contato afetivo/sexual entre seres humanos, levando em consideração apenas a anatomia sexual, ou seja, feminino/fêmea/passiva e masculino/macho/ativo (PETRY \& MAYER, 2011). 
vista epidemiológico, mas, também, frente aos reduzidos dados de pesquisas realizadas juntamente à saúde desta população, passando a ser necessária a consideração das condições concretas de vida e das representações sociais vinculadas a estes atores sociais, tendo em vista que, em sua maioria, os agravos à saúde desse segmento populacional estão diretamente relacionados e determinados socialmente.

A presente pesquisa foi realizada através de análises quantitativa e qualitativa com coleta de dados a partir de formulários compostos por questões fechadas e abertas, aplicados às travestis que se prostituem, no município de Confresa no mês de novembro de 2015. Para aplicação dos formulários, inicialmente, ocorreu um contato direto com um destes atores sociais, que indicou novos participantes, formando assim uma rede de contatos. Uma vez identificados e contactados, os mesmos indicaram o local e hora para que, individualmente, estivessem à vontade no ato da realização da aplicação do formulário.

Muito se sabe sobre as dificuldades passadas pela população brasileira quando se trata de saúde pública, no entanto pouco se sabe sobre as dificuldades que uma parcela especifica da população (gays, lésbicas, bissexuais, travestis e transexuais) sofre com os atendimentos, devido ao preconceito por sua orientação sexual, pois devido a uma variada gama de preconceitos, os homossexuais demoram mais a procurar os serviços de saúde. Esta relação entre homossexualidade e saúde tem sido discutida com muita frequência no último século, passando a ser motivo de debates e contestações tanto no campo das ciências médicas quanto das ciências sociais.

Tal fato impõe alguns questionamentos: Até que ponto o preconceito interfere nos atendimentos dos estabelecimentos de saúde de Confresa-MT? Como se porta o profissional perante um indivíduo homossexual? Como os travestis que se prostituem veem a qualidade do atendimento dos profissionais da saúde e o cumprimento das políticas públicas de saúde para a população LGBT no município de Confresa-MT?

\section{Sexualidade e Gênero}

As discussões sobre sexualidade e gênero vêm sendo desenvolvidas no mundo acadêmico, entre outras maneiras, através de teorias que, em sua variedade, mostram o quão grande são as contradições e normatizações relacionadas a estas questões sob as ópticas sociológica e antropológica.

Em se tratando de sexualidade pode-se dizer que a mesma é algo vasto, que pode envolver diferentes fatores, sendo eles sociais e emocionais, estabelecidos através das relações com o meio social e com o outro, tornando-se algo particular e único em cada ator social. Sobre o conceito de sexualidade, Figueiró (2006), expõe que,

\footnotetext{
Sexualidade, por sua vez, inclui o sexo, a afetividade, o carinho, o prazer, o amor ou o sentimento mútuo de bem querer, os gestos, a comunicação, o toque e a intimidade. Inclui, também, os valores e as normas morais que cada cultura elabora sobre o comportamento sexual. (FIGUEIRÓ, 2006: 2).
}

E é neste sentido que a sexualidade dentro da história da humanidade, é assinalada por fortes mudanças influenciadas através das percepções e pensamentos que orientam diversas concepções que surgem a partir de 
múltiplos contextos culturais, políticos, econômicos e religiosos. E é devido a estes contextos, que se torna necessária a percepção da sexualidade em seu contexto histórico e social para possibilitar a desconstrução de qualquer visão fragmentada e descontextualizada que possa surgir sobre este assunto.

Para Szasz (2004) a sexualidade humana não é algo influenciável, mas sim, construído através de relações, culturas e controles impostos pela sociedade. E partindo destas relações, o conceito de sexualidade não se reduz à ideia de uma ação relacionada diretamente com específicas partes do corpo, mas sim, passa a ser desenvolvido por considerar não somente atributos que envolvem o corpo, como desejos eróticos, fantasias, sensações, práticas e hábitos, mas também relações construídas na vida em sociedade, tais como concepções, valores, discursos e todo um emaranhado de significados construídos socialmente relacionados aos desejos e às condutas sexuais.

Portanto, os princípios heteronormativos, são produtos de uma construção histórica, e neste sistema simbólico em que vivemos, o contato sexual ativo estaria apenas destinado ao homem, enquanto a sexualidade passiva aparece tipicamente feminina. Deste modo, o penetrador é o dominante, o detentor do poder, portanto, o homossexual passa a ser feminino, pois assumiria o papel da mulher em uma relação sexual, indo contra a natureza humana, sendo que para o teórico, tal natureza nada mais é que uma hierarquia social (BOURDIEU, 2010).

Já em se tratando de gênero, seu conceito para as ciências humanas e sociais está inteiramente ligado à construção social do sexo biológico, sendo que o mesmo foi criado com o objetivo de realizar uma distinção entre o fator anatômico e o fator social. Portanto as teorias sociais não colocam em jogo a condição dos seres humanos nascerem do sexo masculino ou feminino, mas sim que o processo de aprendizado do que é ser homem ou o que é ser mulher é produzido e designado pela cultura. Colocando o gênero como um produto da realidade social em que está incluso, e não em decorrência do seu corpo anatômico, portanto, indivíduos apresentados como masculinos podem apresentar gestos tidos como femininos em algum contexto social, podendo também manter relações sexuais com indivíduos do mesmo sexo, mesmo que contrariando o que é dito como "normal" pela sociedade.

Para Scott (1995), o gênero está diretamente relacionado a uma construção cultural das características ditas masculinas e femininas. O ser macho ou fêmea é entendido culturalmente, porém, a idéia atribuída ao que é masculino e feminino pode variar de cultura para cultura, além de sofrer variações na dimensão histórica.

E é baseado nestas teorias que Parker (2000) destaca que o modelo cultural pode influenciar na junção da sexualidade com gênero, encobrindo a questão de gênero dentro do ponto mais vasto da sexualidade.

E na tentativa de promover tal diferenciação Bourdieu (2010) destaca que o princípio da visão social é o fator predominante na construção das diferenças anatômicas de ambos os sexos, evidenciando uma relação de dominação no que diz respeito à subjetividade que proporcionam divisões objetivas, tendo como referências ao macho (pênis, virilidade, penetrador, potência), já à fêmea, estão relacionados os termos específicos (vagina, fragilidade, penetrada, maternidade, submissão), tudo o que tange o universo feminino passa a ser inferiorizado em relação ao masculino. 


\section{Travestilidade e Prostituição}

Para Kulick (2013), a travestilidade4 trata-se de um fenômeno exclusivamente masculino, pois define as travestis como homens que não possuem o desejo de serem mulheres, como é o caso dos transexuais; estes não desejam retirar seu pênis ou fazer mudanças em seus corpos, porém se auto identificam como homossexuais. Para o autor, as transformações que as travestis realizam em seus corpos são promovidas apenas com o fim de captação de parceiros do mesmo sexo, elaborando uma mulher para se relacionar com homens, em função, apenas, de sua identidade sexual.

Portanto, travestis são homens que transformam seus corpos em femininos, através de ingestão de hormônios, utilização de silicones, e que permanecem travestidas em seu dia-a-dia. Buscando esta imagem feminina, removem-se os traços masculinos, bronzeiam-se, usam roupas glamorosas e escolhem nomes de artistas famosas (PELÚCIO, 2005).

O processo de empreendimento desenvolvido para ser uma travesti exige do indivíduo mudanças em seu corpo, nos cuidados e na aparência, tornando-se uma associação de fatores que dão origem a um corpo feminino, com gestos, atitudes e designações que levam esses indivíduos a se passarem por mulheres, ou pelo menos apresentarem a aparência de mulher.

Os territórios de prostituição são os principais lugares sociais de aprendizagem e construção do gênero feminino para as travestis, pois tais ambientes (públicos ou privados) passam a servir de camarim e palco para este processo de transformação de gênero, pois é neste local que adquirem a aprendizagem dos métodos e das técnicas para a transformação do corpo, incorporando os valores e as formas femininas, além dos truques e das técnicas da prostituição, dando origem a gostos e preferências e apreendendo os hábitos de uma travesti, sendo estes territórios, os "espaços onde as travestis se constroem corporal, subjetiva e socialmente" (BENEDITTI, 2000: 58).

O processo de prostituição pode levar as travestis a alterações corporais que muitas vezes culminam em óbito devido às negligências pessoais ou de outrem. No entanto, além destas alterações, o processo de saúde/doença das travestis está condicionado, também, pelo contato intenso com as Doenças Sexualmente Transmissíveis (DST) e HIV/Aids5, com as drogas e álcool, com as diversas forma de violência vivenciadas (física, violência verbal, institucional, etc.) e até mesmo com a negligência e/ou preconceitos por parte de alguns profissionais, seja da saúde ou de outros serviços públicos ou privados, ao receberem as travestis de forma estigmatizante que compromete o atendimento necessário para a resolução de suas problemáticas.

4 Peres (2004: 120) defende o termo travestilidade, como oposição ao termo travestismo, pois, segundo o mesmo, esse termo pode contemplar "a imensa complexidade das formas de expressão travesti existentes, considerando a heterogeneidade dos modos de ser no mundo que é configurado pela sub-cultura travesti”.

5 Vírus da Imunodeficiência Humana/Síndrome da imunodeficiência Adquirida 


\section{Saúde à População LGBT e Homofobia nos Estabelecimentos de Saúde}

A Constituição Federal de 1988 em seu Art. 1 $^{\mathrm{o}}$, inc. II e III garante a cidadania e a dignidade da pessoa humana, sendo este direito reforçado no Art. $3^{\mathrm{o}}$, inc. IV que dispõe como compromisso da União promover o bem de todos, sem preconceito de origem, raça, sexo, cor, idade e quaisquer outras formas de discriminação. Já o seu Art. $196^{\circ}$ destaca que a saúde é direito de todos e um dever do Estado, sendo garantida através de políticas sociais e econômicas que busquem a redução do risco de doença e de outros agravos e garantam o acesso de forma universal e com igualdade às ações e serviços tanto para a promoção, quanto para a proteção e recuperação desses atores sociais (BRASIL, 1988).

O Programa Direitos Humanos - Direitos de Todos definido no Plano Plurianual de 2004-2007, definiu a ação denominada Elaboração do Plano de Combate à Discriminação contra Homossexuais, e com objetivo de dar efetividade a este compromisso, é lançado no ano de 2004 o Brasil Sem Homofobia - Programa de Combate à Violência e à Discriminação contra GLTB e de Promoção da Cidadania Homossexual, pela Secretaria Especial de Direitos Humanos, que apresenta como objetivo a promoção de cidadania aos gays, lésbicas, travestis, transgêneros e bissexuais, equiparando direitos e combatendo a violência e à discriminação homofóbicas, respeitando as especificidades de todos os grupos populacionais (BRASIL, 2004).

Foi no ano de 2011 que o Ministério da Saúde seguindo as diretrizes expressas no Programa Brasil Sem Homofobia, implementou a Política Nacional de Saúde Integral LGBT com o intuito de que a mesma passasse a ser implantada no Sistema Único de Saúde (SUS) através de um conjunto de diretrizes com planos que contenham estratégias e metas sanitárias para sua operacionalização, sendo este um compromisso proposto para todas as instâncias do SUS (gestores, trabalhadores da saúde, técnicos e conselheiros), com o objetivo de promover a saúde integral da população de lésbicas, gays, bissexuais, travestis e transexuais, eliminando a discriminação e o preconceito institucional, contribuindo, assim, no combate as desigualdades e a consolidação do SUS como sistema que aborda o usuário de forma universal, integral e equitativa (BRASIL, 2011).

Calderaro et al. (2008) destacam que no campo da saúde direcionada à população LGBT, faz-se necessária que os princípios que norteiam o Sistema Único de Saúde - a universalidade, a integralidade e a equidade - se materializem em políticas públicas que possam promover o enfrentamento das diversas consequências decorrentes da exclusão ocasionada pela homofobia e pela internalização da heteronormatividade, pelos profissionais da saúde, a ponto de promoverem um atendimento sem as especificidades condizentes à identidade sexual do atendido, ocasionando situações de discriminação e preconceito contra esta parcela da populacional. 
Do contrário, segundo Mello et al. (2012), ainda existirão barreiras simbólicas, morais e estéticas que impedirão o acesso aos serviços de saúde pela população LGBT, de forma a não encontrarem atendimentos de qualidade, sem preconceitos ou discriminação, em especial aos mais pobres ou os que apresentam binarismo de gênero (mulheres "masculinizadas", homens "efeminados”, dentre outros). De acordo com Brasil (2010),

\begin{abstract}
Hoje já existe a consciência da complexidade das necessidades e demandas dessa população e da importância de adequar a rede de serviços do SUS para responde-las de forma resolutiva, integral e com qualidade. No sentido de entender a complexidade do tema, é importante distinguir as especificidades dos diferentes segmentos que integram a população gay, lésbica, bissexual e transexual, pois representam diferentes formas de expressão da orientação sexual e da identidade de gênero. (BRASIL, 2010: 80).
\end{abstract}

Lionço (2008) descreve que através de mobilizações sociais, tem se conquistado os direitos desta população, dentre elas as políticas públicas de saúde voltadas à população LGBT e outras. No entanto, Mello et al. (2011) destacam limitações para a efetivação destas políticas, sendo elas a ineficiência e ausência de previsões orçamentárias para a execução das ações previstas e, com isso, tais ações passam a ser de difícil alcance, destacando ainda que, apesar de as políticas apresentarem boas perspectivas, a materialização das mesmas passa a ser o principal problema, com a apresentação de vários obstáculos, dentre eles a homofobia e a heteronormatividade no contexto institucional.

Pois, tratando-se de atendimentos discriminatórios e preconceituosos em estabelecimentos de saúde, Melo et al. (2011) encontra nas falas dos atores envolvidos em sua pesquisa a presença constante desses atos nos serviços de saúde no país, o que nos leva a perceber o imenso caminho a ser percorrido rumo à conscientização dos profissionais da saúde diante das extremas consequências individuais e sociais causadas pela homofobia.

No entanto, Mello et al. (2011) destaca que o processo de homofobia nos ambientes de saúde está presente, de forma mais intensa, entre as travestis e transexuais pois, além de sofrerem preconceitos, muitas vezes direcionados a marcadores sociais, ainda sofrem por solicitarem serviços que não se encontram à disposição das demais parcelas da população, tais como hormônios, silicone, dentre outros. Neste sentido, pode-se afirmar, que travestis e transexuais são a parcela da população LGBT que mais sofre com a escassez das políticas de saúde específicas a esta população.

Portanto, tornam-se necessárias reformulações nos espaços de saúde para que possa ocorrer a inclusão da população LGBT nas unidades. Tais reformas dependem, entre outras, da transformação no modo de pensar e de agir dos profissionais de saúde, pois a cultura advinda dos padrões heteronormativos passa a influenciar de certo modo, o atendimento dos profissionais da saúde, o que os leva a dar assistência a todos os usuários como se fossem heterossexuais, gerando situações graves de discriminação e preconceito contra os homossexuais. (CARDOSO; FERRO, 2012).

\title{
Dia-a-dia das travestis que se prostituem
}

O município de Confresa-MT vem passando por um momento de ampla difusão no que tange o processo de prostituição entre as travestis que aqui 
residem, demonstrando que com este crescente número, também são necessárias ações que propiciem uma melhor qualidade de vida e processos preventivos destinadas à esta população. Este crescimento é evidenciado através da declaração de uma das entrevistadas,

"Quando comecei a me prostituir aqui em Confresa, era somente eu e uma amiga que íamos para a rua, mas hoje aumentou muito a quantidade de travestis que vão para a BR6, na noite, hoje, acredito que são mais que dez" (Participante 10, 21 Anos).

Ao depararmos, nas ruas, com prostitutas, percebemos o quão grande e intenso é o processo de violência e agressões vivenciado pelas mesmas, principalmente quando observamos a prostituição entre travestis. As chacotas, os palavrões, as piadinhas, as agressões físicas, os assaltos, dentre outros, são frequentes em suas vidas e é neste sentido que a prostituição nas ruas de Confresa-MT, vem tomando rumos preocupantes, devido ao alto índice de violência direcionado às travestis que vivem em prostituição.

"Algumas pessoas passam nas ruas em que estamos trabalhando na noite, e gritam, chingam, fazem piadinhas, nos deixando com muito medo de sofrer agressões" (Participante 10, 21 Anos).

Relatos obtidos, por meio do contato direto com estes atores sociais, nos mostram o descaso das autoridades públicas para com este grupo, mesmo por parte dos agentes policiais, que ao serem acionados para promoverem a defesa de uma travesti, encaram-na como se não tivesse o direito à segurança pública, levando à uma intensa vulnerabilidade.

\footnotetext{
"Outro dia fui agredida e roubaram meu celular, chamei a polícia, e quando viram que se tratava de uma travesti, não deram importância alguma para o que aconteceu, não foram atrás dos agressores e ladrões” (Participante 4, 23 Anos).
}

Entre as travestis, o mundo da prostituição é representado por incalculáveis processos de mudanças, seja no modo de vestir, de agir, de pensar e até mesmo na transformação de seu próprio corpo, fazendo deste mundo uma constante e glamurosa representação, muitas vezes teatral, em que as ruas ou esquinas, passam a ser o palco desta formidável peça. No entanto, pouco se sabe do que realmente ocorre em seus bastidores, que devido suas características e especificidades, o apresento através da expressão "Submundo da Prostituição".

E adentrando a este "submundo" pude perceber que a vulnerabilidade entre as travestis se faz presente em diversos aspectos, sendo as condições de moradia, precárias, alimentação inadequada, violências constantes, tanto por parte dos familiares, sociedade e pelos próprios clientes, saúde sem especificidade e equidade, distanciamento da educação, enfim, vivem em um constante processo de sofrimento psicossocial. Porém é na noite, que esta vulnerabilidade aumenta, e é neste momento em que as travestis sofrem seus maiores tormentos, muitas vezes escondidos por detrás das intensas transformações e representações. 


\begin{abstract}
motoristas, transeuntes, gente que passa em automóveis e ônibus. Na maioria das vezes, a violência vem em forma de agressão verbal, mas não são raros os casos em que gangues de jovens espancam travestis. Também é comum ver gente que passa de carro lançar pedras e garrafas sobre elas. Algumas vezes chegam a disparar armas de fogo contra travestis em plena rua. Normalmente as pessoas que cometem esses crimes não são identificadas nem detidas. E quando o são, recebem penas leves da justiça. (KULICK, 2013: 47).
\end{abstract}

No entanto, a prostituição não é vista pelas travestis como um processo totalmente perverso, pois através de conversas informais pode-se perceber que há a presença do prazer no ato de prostituir-se, mesmo que a aquisição financeira seja a motivação principal. Em muitos momentos relatam que o desejo e prazer são fatores que também às levam a este mundo em que a sensação de serem desejadas torna-se muitas vezes, superior aos preconceitos e as violências vivenciadas na noite. Kulick (2013) também relata em sua etnografia a presença do prazer diante da prostituição, pois para as travestis, o ato de prostituir-se reforça sua auto-estima, a ponto de proporcionar satisfação sexual.

Durante o dia, buscam não freqüentar as ruas da cidade, porém quando o fazem, não se intimidam com as chacotas e agressões destinadas à elas, pois o convívio com esta realidade, as fizeram moldar seus pensamentos de modo à não levarem em considerações tudo o que as é exposto. No entanto, isso nem sempre acontece, pois há momentos que tais perturbações fazem com que não se contenham, agredindo, muitas vezes verbalmente, o seu agressor, porém como elas mesmas citam, nestes casos, elas são sempre consideradas "erradas", ficando o agressor como a vítima.

"Se me humilha, eu humilho mais ainda. Cansei desse preconceito! Mas sempre que acontece alguma coisa, as culpadas somos nós” (Participante 3, 21 anos)

É nesta realidade, que as travestis de Confresa-MT vivem constantemente, sem segurança pública, saúde ou qualquer outra política que as levem a uma vida mais digna e com menos limitações, onde possam mudar esta triste realidade a que se submetem, por terem reduzidas condições de se sobressaírem a todo esses processo excludente.

A presente pesquisa foi realizada no mês de novembro de 2015, através da aplicação de formulários para dez travestis que se prostituem no municipio de Confresa-MT. O número de formulários aplicados se deu pelo contato de uma travesti em seu ambiente de prostituição, que indicou outras e, através da formação dessa rede social foi-se indicando umas às outras e, conforme as indicações, as mesmas eram contactadas via celular ou procuradas no seu endereço de domicílio, de modo que alcançamos um total de 13 (treze) contatos, sendo que apenas 10 (dez) se dispuseram a participar da pesquisa.

A vida noturna das travestis tornou a pesquisa um pouco mais complexa do que o esperado, pois durante o turno em que se prostituem, as mesmas não aceitavam responder aos formulários. Durante a manhã, as mesmas estavam em repouso e, a tarde, geralmente, envolviam-se nos cuidados com seus corpos. Mesmo assim, foi neste período vespertino, que prontificaram-se a participar e, em sua totalidade, a aplicação dos questionários se deu em seus lares.

Das dez travestis que participaram, quatro vivem em casas de prostituição durante o período diurno e seis em casas próprias, porém todas saem às ruas no período noturno, sem hora para voltarem para seus lares, descansando apenas às segundas-feiras. 
$\mathrm{Na}$ tentativa de caracterizar as travestis participantes, pode-se perceber que, no que tange à faixa etária, 50\% das travestis encontram-se entre 15 e 20 anos de idade, e os outros 50\% entre 21 e 30 anos.

Podemos destacar, que a presença de pouca idade entre as travestis em prostituição, talvez se dê, devido a falta de oportunidade do convívio famíliar, pois costumam saír muito cedo de casa, fato este ocasionado muitas vezes pela falta de aceitação da família, ou até mesmo para que possam ter maior privacidade, morando sozinhas. No entanto, muitas vezes o ato de morar só passa a ser um problema, tendo em vista a escasses de trabalho para menores, dificultando ainda mais se este for uma travesti, levando-as, antes mesmo de completarem a maioridade, para a vida na prostituição, em prol de seu sustento.

Já em relação à escolaridade, podem-se perceber que não houveram participantes com nível superior ou acima, 20\% não concluiram o ensino fundamental, $30 \%$ possuem o ensino fundamental completo, $40 \%$ possuem o ensino médio incompleto e apenas 10\% concluíram o ensino médio. Segundo Teixeira (2008) a baixa escolaridade entre as travestis se deve ao bullying, as agressões e as zombarias presentes na escola, que as levam a uma evasão precoce deste ambiente, aumentando assim cada vez mais as dificuldades para aderirem à um emprego formal.

Portanto, Leite e Santos (2009) afirmam a necessidade de uma educação em que haja a relação das questões da interculturalidade e dos movimentos de minorias sexuais, pois a discriminação baseada no preconceito e na intolerância possui um cunho cultural, tornando-se necessária uma educação que não estigmatize, não discrimine e nem reduza nenhum ser humano em decorrência de sua cor, sexualidade, cultura, idade, dentre outros, permitindo a valorização das singularidades e das diferenças.

Quando questionadas sobre sua orientação sexual e status conjugal, 100\% consideram-se travestis e solteiras. Quando solicitadas tais respostas, ambas sorriam ao se declararem solteiras e travestis, pois no mundo em que vivem, relatam não terem condições de namorarem ou casarem, pois segundo a participante 4 (23 anos) "somos prostitutas e travestis, e ninguém casaria com uma pessoa assim".

Este fato nos leva a ponderar a possibilidade de um preconceito internalizado pela própria travesti, pois ao relatar que "ninguem casaria com uma pessoa assim", esta se auto estigmatizando, considerando-se inapta à uma união conjugal, em prol de sua orientação sexual e de sua profissão.

A ausência de uma união estável, ou pelo menos de um relacionamento constante e fixo, pode levar às travestis a procurarem prazer em outros momentos de sua vida, pois como citado anteriormente e corroborado por Kulick (2013), as mesmas remetem a presença do prazer no ato de prostituir-se, pois, talvez, este seja um dos poucos momento em que se relacione sexualmente e de certa forma, afetivamente, com alguem, que sinta desejo em possuí-la, pois a procura pelo sexo é advinda do próprio cliente, elevando assim sua autoestima e sentimento de ser desejada.

Já no que diz respeito às questões de saúde da população de travestis em prostituição, pode-se constatar que 70\% desta população não possuem conhecimento diante de seus direitos por uma saúde especifíca e condizente com suas reais necessidades e vulnerabilidades. No entanto, as travestis que relatam possuir conhecimento diante das políticas públicas de saúde para a população LGBT, destacam como iniciativas, apenas a realização de exames de HIV, Sífilis e Hepatites e ainda a distribuição de preservativos e lubrificantes, o 
que mostra que os 30\% dos participantes que relatam possuir conhecimento sobre as políticas, na realidade não o possui, este desconhecimento pode ocorrer devido ao não contato com ações destinadas às próprias, pois ao analisar os relatórios de gestão municipal de saúde de 2010 a 2013, Kremer (2014), em sua pesquisa, identifica apenas ações de prevenção de DST/Aids entre a população LGBT no municipio de Confresa-MT, através do SAE/CTA7, o que leva as travestis a relacionarem políticas públicas de saúde apenas às esses atos que lhes são apresentados.

Tal fato pode também estar relacionado ao reduzido grau de escolaridade entre as travestis, portanto não buscam por seus direitos, muitas vezes por desconhecê-los ou por não lhes serem ofertados, o que leva cada vez mais a vulnerabilidades entre as mesmas e ao não uso dos serviços disponíveis para a recuperação de seu processo de saúde/doença, ou ainda para prevenção de patologias ou agravos, a elas relacionadas, tornando clara a necessidade de ações que promovam a exposição de seus direitos, assim como das ações que se fazem presente nos estabelecimentos de saúde ou em outras instituições.

Quando questionado às travestis quanto à utilização dos serviços públicos de saúde do município, 90\% delas relatam já ter utilizado destes serviços pelo menos uma vez, sendo que dentre os estabelecimentos citados, podemos destacar, em primeiro lugar, o SAE/CTA, seguido do Hospital Municipal e da Estratégia da Saúde da Família, consecutivamente. Tais estabelecimentos são tomados como referência pelas mesmas, tendo em vista o fácil acesso e possíveis resolutividades em suas problemáticas. As travestis referem-se ao SAE/CTA apenas para a realização de Testes Rápidos e aquisição de preservativos e lubrificantes, o Hospital é referenciado apenas em momentos de emergência e as ESF's8 são citadas, porém relatam não encontratem resolutividades em suas problemáticas nestes estabelecimentos.

Estes dados demonstram que a população de travestis em prostituição, promovem de forma significativa a procura por estabelecimentos públicos de saúde, porém desconhecem a vasta gama de atendimentos ofertados por estes estabelecimentos, deixando claro a necessidade de apresentação destas atividades para este público alvo.

A resolutividade de seus processos de saúde/doença se fez presente em aproximadamente $67 \%$ dos casos de procura, o que é um número considerável. Porém pensando de uma forma geral, um percentual de $33 \%$ de não resolutividade torna-se preocupante, ainda mais se considerarmos uma população em situação de extrema vulnerabilidade, como as travestis em prostituição, pois a violência, agressões, DST's, dependência química ou alcoólica, precárias condições de vida e intervenção no próprio corpo, nem sempre adequadas, se fazem presentes no cotidiano das mesmas, levando-as cada vez mais ao adoecimento.

As travestis relalataram em seus depoimentos que, além da não resolutividade de seus problemas, durante os atendimentos e/ou processo de recuperação/internação eles passam por intensos constrangimentos.

\footnotetext{
"Quando fiquei internada no hospital, depois de ser agredida por um cliente caminhoneiro, fiquei três dias em uma sala isolada na enfermaria masculina, até parecia que eu tinha uma doença que passasse para os outros, sai de lá muito mal, queria mesmo era ficar na enfermaria feminina" (Participante 4, 23 anos).
}

7 Serviço de Atenção Especializada/Centro de Testagem e Aconselhamento

8 Estratégia da Saúde da Família 


\begin{abstract}
"Quando procurei o postinho de saúde para me passarem um "remédio de evitar", hormônio, me falaram que não podiam fazer isso" (Participante 1, 21 anos).

“O médico mal me escutou, foi logo passando remédio, nem olhou na minha cara, fiquei com medo de tomar o remédio, porque ele nem sabia o que tinha de verdade, tomei um que eu tinha costume de tomar em casa" (Participante 5, 19 anos).
\end{abstract}

Tais relatos nos levam a questionar, até que ponto os profissionais estão aptos a atenderem as populações específicas pertencentes à sociedade confresense?

Para Muller e Knaut (2008) a qualificação dos profissionais da saúde e a aproximaçao entre esses dois segmentos sociais, é o caminho para se modificar este conceito social do que é certo ou errado, além de reduzir os casos de associação das travestis com a promiscuidade e violência, tornando-se neccessário um trabalho conjunto entre os profissionais da saúde, sociedade e Estado, na tentativa de diminuir os danos causados pela discriminação e pelo estigma enfrentados pelas travestis, além de conhecer as necessidades e as demandas dos diversos segmentos sociais, tidos como excluídos.

Kulick (2013) relata em sua etnografia que a maioria da travestis, assim como quase toda a população brasileira, não possui acesso aos serviços básicos de saúde. As travestis, levam a vida se auto diagnosticando e se auto medicando, ou se tratando com medicamentos indicados por terceiros.

\begin{abstract}
No que se refere às demandas das travestis em relação à saúde, estas permanecem circunscritas às DST/Aids, quando elas também querem terapia hormonal, próteses cirúrgicas, exame de próstata, prevenção à calvície, cuidados profiláticos que as permitam serem "belas", isto é, femininas. Pois é no feminino que querem viver. E é essa feminilidade, acreditam muitas, que lhes trará também reconhecimento social. (PELUCIO, 2007: 10)
\end{abstract}

O preconceito e a discriminação estão constantemente presentes nos estabelecimentos públicos de saúde do município de Confresa-MT, pois segundo os dados obtidos através da aplicação dos formulários, $67 \%$ dos entrevistados que já procuraram os serviços públicos de saúde, sofreram algum tipo de preconceito nestes estabelecimentos, sendo que apenas 33\% não relataram sofrer processo estigmatizante.

Quando questionadas sobre quem teria cometido o ato preconceituoso para com elas, convém atentarmos aos seguintes relatos:

"A equipe de saúde me colocaou em uma salinha isolada da enfermaria masculina"
(Participante 4, 23 anos).

"Quando fiquei internada me colocaram na enfermaria masculina e sofri com piadinhas dos pacientes, queria mesmo era estar em casa” (Participante 1, 21 anos). "Quando procurei o postinho de saúde, as pessoas que estava atendendo la na
frente, ficaram rindo, quando passei" (Participante 6, 18 anos).

"Fui no postinho de manha, e quando cheguei vi que tinha um monte de gente fazendo piadinhas, as pessoas que esperavam $e$ as meninas que estavam trabalhando" (Participante 7, 19 anos).

Para Muller e Knaut (2008) o processo de internação entre as travestis é um ponto bastante delicado, pois segundo o modelo vigente do Sistema Único de Saúde - SUS, as mesmas devem ficar hospitalizadas junto aos outros pacientes do sexo masculino, levando em consideração apenas seu sexo biológico, não lhes sendo dada a possibilidade de ficarem em enfermarias 
femininas, ou com outras travestis, pois são vistas apenas como homens que se vestem de mulher.

O preconceito e a discriminação geralmente encontram-se atrelados a uma visão pré-estabelecida sobre os homessexuais, principalmente às travestis, que muitas vezes são estigmatizadas pelos próprios gays, pois têm uma visão que ligam as travestis diretamente às drogas, palavrões, violência, dentre outros, fazendo com que esta percepção não os deixe compreender o que realmente ocorre por trás deste corpo em constante transformação.

Segundo Kulick (2013) os brasileiros costumam chacotear os interesses das travestis quanto à sua feminilidade por diversas razões, sendo uma delas é a estreita associação das travestis com a prostituição, com a Aids, com as drogas e com a violência, associações estas que as levam a sofrer enorme estigma da sociedade, podendo resultar em críticas violêntas e explícita censura por parte de muitos. Kulick (2013) ainda descreve que

\begin{abstract}
Recusar-se a reconhecer o gênero das travestis é um meio prontamente disponível de rejeitar seu próprio direito de existir. É uma maneira de colocar as travestis de volta em seu lugar (supostamente decente do pronto de vista do gênero). Ao mesmo tempo é uma maneira de negar e de se resguardar contra as possibilidades que se abrem para os homens de deslizarem de uma categoria para outra nesse sistema gênero. (KULICK 2013: 245).
\end{abstract}

Fry (1982) destaca em sua teoria que a homossexualidade em ambientes rurais ou em cidades do interior é vista através do que o autor destaca como "modelo hierarquico", que em sua totalidade passa a ser a representação de gênero destinada às questões de passividade e atividade, destacando que o homem ativo que se relaciona com outro, não trata-se de uma identidade homossexual, sendo que o verdadeiro homossexual, passa a ser o passivo ou que apresente as características da feminilidade, mesmo que esta esteja atrelada apenas à questão da passividade. Partindo deste pressuposto, o indivíduo que se relaciona com as travestis não é visto como homossexual, desde que tenha assumido uma posição ativa na relação sexual, sendo a travesti a real transgressora das "moralidades" e dos "bons costumes" aludidos na sociedade, colocando esta novamente em constantes processos de preconceito e depreciação, quando comparado aos homossexuais ativos ou masculinizados.

Fatos discriminatórios, tornam o atendimento menos efetivo, levando os usuários à negarem sua identidade sexual no ato da apresentação, devido a falta de confiança, e fazendo com que os profissionais que realmente sejam comprometidos, não realizem suas condutas levando em consideração suas especificidades, proporcionando assim um atendimento, na maioria das vezes, ineficaz ou com baixo grau de resolutividade.

$\mathrm{O}$ uso do nome social é um direito de qualquer indivíduo, e entre as travestis se torna mais importante pelo fato de reafirmarem seu gênero, seus sentimentos, seus desejos, enfim, seus direitos. Conforme resultado desta pesquisa, o uso do nome social se faz presente por todas as participantes, mas este não é utilizado em cadastros e documentos da saúde por $50 \%$, muitas vezes em função do receio de chacota, por desconhecimento desse direitos, ou até mesmo por vergonha de ter negada esta opção, motivações estas que podemos compreender atraves da transcrição dos depoimentos abaixo:

"Tenho medo de não aceitarem" (Participante 6, 18 anos).

"Não sabia que podia usar" (Participante 3, 21 anos). 
Bittencourt et. al.(2014), discorre que chamar as travestis por seu nome masculino nos atendimentos em saúde, é apontar a "irregularidade" e a "inconformidade" que o(a) profissional de saúde está aplicando àquela pessoa. No entanto, a recusa de médicos e outros profissionais em chamá-las a partir de seu nome social é um fator que geralmente contribui para o constrangimento gerado nestes serviços, gerando o conseqüente afastamento das travestis pela procura por atendimento em estabelecimentos de saúde.

Segundo São Paulo (2014: 83), "o respeito a qualquer pessoa começa com o uso do nome social. Isso deve ser levado em consideração durante o atendimento de travestis e transexuais, porque esse é o primeiro passo para a construção de uma relação confiável e saudável entre profissional e usuário”.

Ao realizar a análise dos dados obtidos através da presente pesquisa, podese perceber, pelos relatos das travestis entrevistadas, que a saúde pública do município de Confresa-MT deixa a desejar, em relação aos atendimentos específicos à esta população, tendo em vista a falta de resolutividade dos mesmos, o preconceito presente tanto por parte dos profissionais, quanto por parte dos próprios pacientes, a falta de ações destinadas aos homossexuais, o desconhecimento por parte dos usuários travestis quanto aos seus direitos e serviços de saúde e a ineficiência das políticas públicas de saúde voltadas à esta minoria marginalizada.

\section{Considerações Finais}

Em resposta aos questionamentos promovidos na introdução desta pesquisa, podemos destacar que o preconceito interfere, mesmo que de forma mascarada, nos atendimentos dos estabelecimentos de saúde pública, principalmente, quando há referência ao médico que, se quer, realizou uma avaliação para propor a medicação ou no momento em que ao procurar o PSF, foi-lhe negado o acesso ao tratamento hormonal e se quer foi encaminhada para tal, no entanto, não podemos generalizar tais atitudes, pois sabemos que muitos profissionais se portam adequadamente diante destes pacientes, deixando de lado seus conceitos já estabelecidos e promovendo atendimentos esclarecedores e pertinentes aos mesmos.

Quanto ao comportamento de profissionais diante de travestis, devemos relembrar o momento em que uma das entrevistadas relata sofrer com chacotas e risadas recebidas de profissionais que se encontravam na recepção de uma unidade de saúde, pois diante de uma situação como esta, acaba por se estabelecer um bloqueio diante do atendimento, fazendo com que muitas vezes esta usuária do SUS, abra mão do atendimento em função de atitudes assumidas por muitos profissionais, lembrando que estes atos hostis não vêm somente destes, partem também dos próprios pacientes que esperam por atendimento.

No entanto, quando, o que entra em jogo, é a qualidade dos atendimentos ofertados, as entrevistadas deixam bem explicitas suas indignações, demonstrando que seus problemas não são integralmente sanados. Muito pelo contrário, geralmente são expostas a processos, que comprometem ainda mais seu estado de saúde, assim como, quando às colocam internadas em salas de isolamento, ou juntamente com homens heterossexuais. 
Diante das necessidades que esta população possui, pode-se perceber a precariedade de ações direcionadas à sua realidade, deixando de lado, atividades que direcionem a promoção da integralidade e da equidade para com esses indivíduos, não lhes ofertando o que realmente se faz necessário.

Partindo do pressuposto de que há a necessidade de uma atenção mais direcionada, deve-se ter em mente que a travestilidade incorre em hábitos corporais ou mesmo práticas sexuais que podem guardar alguma relação com o grau de vulnerabilidade destas pessoas.

No entanto, o maior e mais profundo sofrimento é aquele decorrente da discriminação e do preconceito. Os desafios na reestruturação dos serviços, das rotinas e dos procedimentos na rede do SUS serão relativamente fáceis de serem superados. Mais difícil, entretanto, será a superação do preconceito e da discriminação que requer, de cada um e da coletividade, mudanças de valores baseadas no respeito às diferenças.

Nesse sentido, as equipes de saúde devem identificar as necessidades de saúde desta população, articular-se com outros setores de políticas sociais no município, com o objetivo de contribuir no processo de melhoria das condições de vida da população LGBT, implantando práticas educativas na Unidade de Saúde com abordagem integral nos aspectos de promoção da saúde e medidas preventivas.

Quanto ao acesso aos serviços de saúde, a população LGBT deve tê-lo assegurado como qualquer outro individuo da sociedade, tendo, porém, suas diferenças respeitadas. Precisam ser informadas de que forma serão atendidas e examinadas, e terem vínculo de confiança com os profissionais de saúde para que possam relatar a sua orientação sexual, caso queiram. Devido à homofobia, algumas pessoas LGBT podem sofrer violência física e psíquica na família, no trabalho e em lugares públicos resultando em omissão da sua orientação sexual, gerando sofrimentos psicossociais que, em casos mais graves, podem levar ao suicídio. Às vezes as pessoas nem manifestam sua identidade de gênero para não sofrerem maiores discriminações.

Outro aspecto de relevância relacionado às questões LGBT, é a necessidade da produção de conhecimentos voltados à saúde desta população, que ainda apresenta-se centrada nas vulnerabilidades às DST/Aids, deixando de lado outros temas e considerações de saúde direcionadas às mesmas.

\section{Referências Bibliográficas}

BENEDETTI, M. A batalha e o corpo: breves reflexões sobre travestis $e$ prostituição. Programa de Pós-Graduação em Antropologia Social, Universidade Federal do Rio Grande do Sul. Porto Alegre, 2000.

BITTENCOURT, D.; FONSECA, V.; SEGUNDO, M. Acesso da população LGBT moradora de favelas aos serviços públicos de saúde: entraves, silêncios e perspectivas. Rev. Eletrônica Conexões PSI. Rio de Janeiro v. 2, n. 2, p. 6o-85, jul./dez. 2014.

BORDIEU, Pierre. A dominação masculina. Rio de Janeiro: Bertand Brasil, 2010. 
BRASIL. Constituição de 1988. Constituição da República Federativa do Brasil. Brasília, DF: Senado Federal: Centro Gráfico, 1988.

Ministério da Saúde. Lei Federal $n^{\circ} 8.080$, de 19 de setembro de 1990. Brasília, DF, 1990.

Conselho Nacional de Combate à Discriminação. Brasil sem homofobia: programa de combate à violência e à discriminação contra GLTB e promoção da cidadania homossexual. Brasília, DF: Ministério da Saúde, 2004.

- Ministério da Saúde. Caderno de Atenção Básica: Saúde sexual e saúde reprodutiva. Série A, Normas e manuais técnicos. Caderno $n^{o} 26$. Brasília-DF, 2010.

Ministério da Saúde. Política nacional de saúde integral de lésbicas, gays, bissexuais, travestis e transexuais. Brasília, DF: Ministério da Saúde, 2011.

CALDERARO, F.; FERNANDES, B.; MELLO, L. Cidadania TTLBG e o direito à saúde no Brasil. 2008 In: ROCHA, Dais et al. (orgs.). Diversidade e equidade no SUS: parceria universidade e educação popular. Goiânia: Cânone. p. 57-68.

CARDOSO, M. R.; FERRO, L. F. Saúde e População LGBT: Demandas e Especificidades em Questão. Psicologia: ciência e profissão, v. 32, n.3, p.552563, 2012.

FIGUEIRÓ, M. N. D. Educação sexual: como ensinar no espaço da escola. Linhas, Santa Catarina, v.7,n.1, p.1-21, 2006.

FRY, Peter. Da hierarquia à Igualdade: a construção histórica da homossexualidade no Brasil. In: FRY, Peter. Para Inglês Ver: identidade e política na cultura brasileira. Rio de Janeiro, Zahar, 1982.

KREMER, C. G. Ações públicas de saúde voltadas à população GLBTT no Município de Confresa-MT. Trabalho de Conclusão de Especialização de Gestão em Saúde/UFMT-UAB. São Félix do Araguaia - MT, 2014.

KULICK, D. Travesti: prostituição, sexo, gênero e cultura no Brasil, trad. César Gordon, Rio de Janeiro, Fiocruz, $1^{\text {a }}$ reimpressão, 2013.

LEITE, A. M. P.; SANTOS, L.N. Identidades Trasns/desviantes. SEMIEDU, 2009. Disponível em: http://www.ie.ufmt.br/semiedu2009/gts/gt2/ComunicacaoOral/AMANDA\%2 oMAURICIO\%20PEREIRA\%20LEITE.pdf. Acesso realizado em 14 de Dezembro de 2015 .

LIONÇO, T. Que Direito à Saúde para a População GLBT? Considerando Direitos Humanos, Sexuais e Reprodutivos em Busca da Integralidade e da Eqüidade. Saúde Soc. São Paulo, v.17, n.2, p.11-21, 2008. 
MELlO, L.; PERILO, M.; BRAZ, C. A.; PEDROSA, C. Políticas de saúde para lésbicas, gays, bissexuais, travestis e transexuais no Brasil: em busca de universalidade, integralidade e equidade. Sexualidade, Salud e Sociedad Revista Latinoamericana, Rio de Janeiro, n.9, p. 7-28, 2011.

MELLO et al. Políticas públicas para a população LGBT no Brasil: notas sobre alcances e possibilidades. Cadernos Pagu , n.39, julho-dezembro de 2012.

MULLER, M. I.; KNAUTH, D. R. Desigualdades no SUS: o caso do atendimento às travestis é 'babado'! Cadernos EBAPE.BR, v. 6, n. 2, p. 01-14, jun. 2008.

PARKER, R. Cultura, economia política e construção social da sexualidade. In: Na contramão da AIDS: sexualidade, intervenção, política. Rio de Janeiro: ABIA \& São Paulo: Ed.34, 2000.

. Eu me cuido, mona": saúde, gênero e corporalidade entre travestis que se prostituem. Seminário Homofobia, Identidades e Cidadania GLBTTT, 2007. Disponível em: http://www.mobilizadores.org.br/wpcontent/uploads/2014/05/texto-5363c70e4coaf.pdf. Acesso realizado em $11 \mathrm{de}$ março de 2016.

PELÚCIO, Larissa. Na noite nem todos os gatos são pardos. Notas sobre a prostituição travesti. Cadernos Pagu. julho/dezembro de 2005. Disponível em: < http://www.scielo.br/pdf/cpa/n25/26528.pdf >. Acesso realizado em $11 \mathrm{de}$ março de 2016.

PERES, W. S. Travestis: subjetividades em construção permanente. In: UZIEL, A. P.; RIOS, L. F.; PARKER, R. G. (Org.). Construções da Sexualidade: gênero, identidade e comportamento em tempos de Aids. Rio de Janeiro: Pallas, 2004.

PETRY, A. R. \& MEYER, D. E. E. Transexualidade e heteronormatividade: algumas questões para a pesquisa. Textos \& Contextos (Porto Alegre), v. 10, n. 1, p. 193 - 198, jan./jul. 2011.

SÃO PAULO. Governo do Estado. Secretaria da Justiça e da Defesa da Cidadania. Coordenação de Políticas para a Diversidade Sexual. Diversidade sexual e cidadania LGBT. São Paulo: SJDC/SP, 2014. Disponível em: <http://www.recursoshumanos.sp.gov.br/lgbt/cartilha_diversidade.pdf $>$. Acesso realizado em 17 de março de 2016.

SCOTT, Joan Wallach. Gênero: uma categoria útil de análise histórica. Educação \& Realidade. Porto Alegre, vol. 20, nº 2. 1995.

SZASZ, I. El discurso de las ciências sociales sobre las sexualidades. In: CÁCERES, C. F. Cidadania sexual en América Latina: abriendo el debate. Lima, Universidade Peruana Cayetano Herida, 2004.

TEIXEIRA, F. B. L' Itália dei Divietti: entre o sonho de ser européia e o babado da prostituição. Cadernos Pagu, 31, 275-308, 2008. 
CESARO, Cleyton Geovani Kremer de

Políticas públicas de saúde à população LGBT

TERTO Jr. V. Homossexulidade e saúde: desafios para a terceira década de epidemia de HIV/AIDS. Horizontes Antropológicos, Porto Alegre, ano 8, n. 17, p. 147-158, junho de 2002. 